Tropical Journal of Pharmaceutical Research, September 2007; 6 (3): 747-754

(C) Pharmacotherapy Group, Faculty of Pharmacy, University of Benin, Benin City, Nigeria. All rights reserved.

Research Article

Available online at http://www.tjpr.org

\title{
Pharmacists as Entrepreneurs or Employees: The Role of Locus of Control
}

\author{
AU Inegbenebor \\ Department of Business Administration, University of Benin. Benin City.
}

\begin{abstract}
Purpose: To investigate whether locus of control distinguished between pharmacists who chose to become entrepreneurs and those who took up employee roles in pharmaceutical establishments.

Methods: The enlarged version of Rotter's I-E scale designed to measure an individual's locus of control was used to survey a sample of pharmacists in two major cities in Southern Nigeria. The sample consisted of 34 pharmacists who were owners/proprietors of retail pharmacies and 35 pharmacists employed in retail pharmacies or hospitals. The difference between entrepreneur pharmacists and employee pharmacists in terms of locus of control was analysed using student's t-test.

Results: The mean locus of control score for entrepreneur pharmacists was significantly different from that of employee pharmacists $(p<0.01)$. Entrepreneur pharmacists had higher scores on the variable than employee pharmacists indicating greater locus of control internality.

Conclusion: Pharmacists characterized by locus of control internality are more likely to assume entrepreneurial rather than employee roles in pharmaceutical undertakings. Such pharmacists are more disposed to adopt innovative pharmaceutical care philosophy. Hence there is need to incorporate entrepreneurial education in the curriculum of pharmacy programmes to encourage positive attitude toward entrepreneurship.
\end{abstract}

Key words: Locus of Control; Entrepreneur Pharmacist; Entrepreneur Education; Employee Pharmacist, Nigeria.

*Corresponding Author: email: aunebor@yahoo.com 


\section{INTRODUCTION}

The Pharmacists Council of Nigeria Act 91 of 1992 grants the right to own and operate a pharmacy only to individuals and corporate bodies that are registered by the Council. An individual pharmacist has the option to practice his/her profession either as an entrepreneur or as an employee. Despite the push and pull factors which operate as driving forces on an individual to enter into an entrepreneurial career, ${ }^{1}$ the decision to become an entrepreneur rather than an employee is a vocational choice ${ }^{2}$. Apart from consideration of perception of desirability and feasibility (including perceived risk) of the entrepreneurial option, certain psychological/personality factors predispose the individual to choose entrepreneurial, instead of employee status ${ }^{3}$.

An entrepreneur is one who creates and grows a new enterprise and demonstrates characteristics of risk taking and innovation ${ }^{4}$. There is ample research evidence that generally support differences between entrepreneurs and employees in terms of their achievement motivation, risk-taking propensity, innovativeness and locus of control ${ }^{5-7}$. Individuals who seek entrepreneurial careers are high in achievement motivation, take moderate risks, have more inclination and ability to innovate and have internal (rather than external) locus of control. Stankiewicz believes that the role of the entrepreneur in the firm has no clear boundaries ${ }^{8}$. Depending on the character and stage of development of the enterprise, the roles may range from articulating the commercial goals of the enterprise, identifying and soliciting the necessary resources to coordinating their use and assuming responsibility for the success of the enterprise. The author insists that even though some of the activities are managerial, the entrepreneur is different from a routine manager.

To Drucker, entrepreneurs are managers who perform their roles in an entrepreneurial way, their primary focus being change rather than maintaining the status quo ${ }^{9}$. Wickham agrees that entrepreneurship is a style of management ${ }^{2}$. According to Covin and Sleovin, entrepreneurial style of management is that in which top managers are inclined to take business risks, are proactive and favour change and innovativeness. A non-entrepreneurial style is characterised by being risk averse, passive, reactive and non-innovative ${ }^{10}$. Clearly, even in this conceptualisation, the entrepreneurial style of management is different from the nonentrepreneurial (routine) style.

Until recently, the emphasis in the curriculum for the training of pharmacists was the enhancement of the professional competence of pharmacists. Even though society entrusted the personal control of pharmacy enterprises to pharmacists only, very little effort was made to develop their entrepreneurial behaviour which is needed to provide innovative pharmaceutical services to the society with corresponding improvement in the financial performance of pharmacies. According to Hindle and Cutting ${ }^{11}$, pharmacists are recognising, though belatedly, the need to be more entrepreneurial in the business of providing professional services in the society. In their study of the professional and financial benefits of a programme designed to enhance the entrepreneurial behaviour of pharmacists, it was found that those who had the entrepreneurial education experienced a higher level of job satisfaction than those who did not. Even though the researchers could not establish a link between entrepreneurial education and financial performance of retail pharmacists, a situation which they attributed to the low quality of data utilized in the analysis, they suggested that "there are still grounds for believing that the link may well exist".

Erah and Nwazuoke ${ }^{12}$ noted that pharmacists in many countries have adopted a much more patient-centred approach in the pharmaceutical services they provide. Nevertheless, in their study of the pharmaceutical care practice standards that are applied by pharmacists in Benin City, Nigeria, $71.3 \%$ acknowledged the feasibility of the pharmaceutical care practice standards, and $72.0 \%$ agreed they were relevant but only $18.2 \%$ applied the standards in their setting while $10.8 \%$ intended to implement the 
standards. Oparah and Eferakeya ${ }^{13}$ surveyed 1005 pharmacists in different practice settings across Nigeria to ascertain their attitude towards pharmaceutical care. The results showed that $75 \%$ of the surveyed pharmacists expressed positive attitude towards pharmaceutical care. Some of the pharmacists (32\%) believed that their current practices were adequately patient caring but $52 \%$ felt there was no need to abandon traditional pharmacy practice. What is evident from these studies is that pharmacists in Nigeria have not adopted the new pharmaceutical care philosophy. The successful implementation of the innovative pharmaceutical care standards critically depends on entrepreneur pharmacists rather than employee pharmacists. It is entrepreneur pharmacists who are more likely to adopt new practice models in responding to perceived opportunities.

\section{Locus of Control}

Locus of control is a personality construct that is defined as perceived control over the events in one's life. It is an individual's general expectancy of the outcome of an event being either within or beyond his/her personal control and understanding $^{14}$. Individuals who believe that the outcome of events are within their personal control and understanding are said to have internal locus of control. Such individuals believe they can affect the outcomes of their lives. On the other hand, those who believe that the outcome of events are beyond their control and understanding are said to have external locus of control. Hence they attribute the outcomes of events in life to fate, chance, luck or to powerful others.

The behavioural consequences of either locus of control internality or externality are instructive. Internal locus of control is associated with a desire to become an entrepreneur ${ }^{15}$, a tendency to exert greater efforts to control the environment, to make better use of information in complex decision making situations, high tolerance of uncertainty and to have greater propensity to behave proactively ${ }^{16}$. Internal locus of control has also been found to be associated with innovative strategies ${ }^{17}$. External locus of control has been shown to be positively correlated with a higher risk of experiencing stress, a lower inclination to take risk and a higher preference for conservative behaviour ${ }^{18}$.

Successful entrepreneurs are characterised by internal locus of control. Brockhaus ${ }^{19}$ showed that successful entrepreneurs exhibited more internal locus of control than unsuccessful ones. He noted that internal locus of control is an asset to advancement in management. For example, employees such as unit managers may be engaged in roles which demand proactivity, tolerance of uncertainty etc. To succeed in such roles, they, like entrepreneurs, must be characterised by internal locus of control. That is, such persons should feel that they are in a position to control their environment by their effort and skill. Accordingly, internal locus of control which translates into greater active efforts to achieve desired results are common to both successful entrepreneurs and successful managers. In other words, this personality construct is not a characteristic that uniquely distinguishes entrepreneurs. However, the "impact of an individual's locus of control personality trait is likely to be more pronounced for entrepreneurs, compared to employees..."

Birdwell and Sullivan ${ }^{20}$ expected that pharmacy owners would have a higher locus of control score compared to staff pharmacists. However, their study showed that there was no significant difference in the mean locus of control scores of the two groups. The researchers cautioned on making generalisation from the results because of the low response rate and the sampling frame they used. They suggested nevertheless that pharmacy colleges should incorporate instructional material related to internal locus of control in their coursework. Praag, Sluis and Witteloostuijn's research ${ }^{18}$, which was based on a representative sample of 6,111 young US citizens interviewed over a period of two decades, showed that entrepreneurs had higher mean locus of control score than employees; and that being internal affects earnings positively with the effect stronger for entrepreneurs than employees. The researchers suggested that locus of control training programmes which seek 
to shift locus of control towards internality might be beneficial to organisations.

\section{Perceptions of Desirability and Feasibility}

Clearly there would be individuals who have the potential of being successful as entrepreneurs (such as being high on the locus of control scale) but who choose to pursue other careers or are unable to start a business because of certain constraints emanating from the economic or social environment.

According to Shapero and Sokol ${ }^{1}$, apart from precipitating events in the form of negative displacement or positive pull to entrepreneurship, the individual's perception of desirability and of the feasibility of entrepreneurship are critical to the decision to start a business.

Perception of desirability may be strong or weak depending on the disposition of the social group, the family, peers, and mentors toward entrepreneurship. Previous work experience may also affect the desirability of starting his/her own pharmacy shop having had a close view of the business and of the person who owns it.

Perceptions of feasibility depend on availability of financial support, encouragement from mentors and nudging from would-be partners. The existence of similar businesses which are successful provide a demonstration effect which enhance the perception of feasibility by an individual.

Except the perceptions of desirability and of feasibility are both positive, an individual is not likely to start his/her own business. It is however individuals who are characterised by internal locus of control that are more likely to perceive the desirability and feasibility of starting a business to be positive.

The aim of this study was to investigate whether entrepreneur pharmacists were different from employee pharmacists in their locus of control score. A study of this nature is important to all those who are concerned with pharmacists in Nigeria transiting to clinical pharmaceutical practice, the adoption of innovative pharmaceutical care as well as those involved in the design of the curriculum for training pharmacists.

\section{METHODS}

Setting:

The study was carried out in Benin City and Asaba, the capital cities of Edo and Delta States of Nigeria. Benin City has a population of $1.08 \mathrm{~m}$. It is the major commercial and industrial centre in Edo State. It has a relatively high concentration of health facilities with a university teaching hospital, a psychiatric hospital, a military hospital, a state-owned general hospital and several private hospitals and clinics. There were 99 registered pharmacies as at January, 2006 most of which were located on the major streets adjoining the hospitals ${ }^{21}$.

Asaba has a population of about 140,604. As a new state capital, the city is experiencing rapid population growth due to in-migration from other towns in the State. There are two major health facilities - a federal government-owned specialist medical centre and a state government-owned general hospital. There are a considerable number of private hospitals and clinics. Asaba had only 15 registered pharmacies at the time of this study and like Benin City, the pharmacies were located on the major streets close to the major hospitals.

Sample and Sampling Procedure: The sample for this study consisted of pharmacists drawn from the population of pharmacists in Benin City and Asaba. Two broad categories of pharmacists were involved in the study pharmacists who are owners/proprietors of retail pharmacies and pharmacists who are employed in retail pharmacies and government hospitals. Identified owner/proprietor pharmacists willing to participate in the study were included in the sample. In the same way, pharmacists who occupy employee roles in retail pharmacies or government hospitals were surveyed. The target was to survey 40 entrepreneur pharmacists and 40 employee pharmacists. There was no effort to match employee pharmacists with entrepreneur pharmacists. 
Research Instrument: The instrument used to measure locus of control was the enlarged version of the Rotter's I-E scale ${ }^{22}$. The enlarged version retained the original Rotter's I-E scale which contained 29 forced-choice items but were interspersed with 14 filler items in order to make the purpose of the test more obscure. Twentythree of the items are pairs of statements, one indicating internal locus of control and the alternative reflected external locus of control. Respondents were required to choose one of the alternatives. The locus of control scale ranges from 0 to 23 , and a score is obtained by counting the number of internal locus of control alternatives chosen by the respondent. Higher scores on the scale reflect more internal locus of control as opposed to external locus of control expectancies.

The reliability of the scale was reported ${ }^{22}$ as Cronbach's alpha $=0.69$. Other items included in the questionnaire for this study were questions to elicit the demographic characteristics of the respondents.

Data Collection: Data was collected between March and May 2005. A research assistant who was a pharmacy student visited the retail pharmacies and major hospitals in Benin City and Asaba to administer the questionnaire. Only pharmacists identified to be either an owner/proprietor of a retail pharmacy or pharmacists who were employed in the retail pharmacies or hospitals were included in the survey. Owner/proprietors of retail pharmacies who were not certified pharmacists were excluded from the study.

The research assistant located pharmacies on the major streets and major hospitals to administer the questionnaire. In most cases, the questionnaire was completed on the spot by respondents and returned to the research assistant. In a few cases, however, the research assistant had to make further calls to collect the completed questionnaire.

Data Analysis: Completed copies of the questionnaire were scored by counting the number of internal locus of control items checked by respondents. The mean score on this variable was computed for the two subsamples and comparison was done using the student's t-test. Descriptive statistics were used to analyse the demographic characteristics of the respondents.

\section{RESULTS}

Forty each of entrepreneur pharmacists and employee pharmacists were located and administered with the questionnaire. Thirty-four of the former and thirty-five of the latter responded giving response rates of $85 \%$ and $85.75 \%$ respectively. Table 1 shows the characteristics of the respondents. Fifty-five of the respondents $(79.7 \%)$ were male while fourteen (20.3\%) were female. The age distribution shows that $34.8 \%$ were between 26 and 35 years of age while $33.3 \%$ were in the 36 45 years age bracket. The number of respondents in the age bracket of 46-55 years was $18(26.1 \%)$ and only $4(5.8 \%)$ were above 55 years. Forty-nine of the respondents $(71.0 \%)$ had the first degree in pharmacy and twelve $(17.4 \%)$ had masters degree. Six $(8.7 \%)$ of the respondents had doctorate degrees and $2(2.9 \%)$ had unspecified qualifications.

Table 2 shows the distribution of entrepreneur pharmacists and employee pharmacists by the number of years they had spent on their respective roles. The mean number of years for entrepreneur pharmacists was 9.9 years with a standard deviation of 5.6 compared to employee pharmacists whose mean number of years was 9.4 with a standard deviation of 8.0 . At $5 \%$ level of significance, there was no significant difference between the entrepreneur pharmacists and employee pharmacists in terms of the number of years in their respective roles. However, an examination of the distributions shows that while the approximate mode of number of years in the role for entrepreneur pharmacists was 8 years, that of employee pharmacists was only 3 years. This suggests that there may be a tendency for young pharmacists who have entrepreneurial tendencies to accept employee status pending the availability of opportunity to assume entrepreneur status. 
The mean of locus of control scores for internality than non-entrepreneurs. It suggests

Table 1: Characteristics of Respondents

\begin{tabular}{|c|c|c|}
\hline Variables & No & \%of Respondents \\
\hline \multicolumn{3}{|l|}{ Sex: } \\
\hline Male & 55 & 79.7 \\
\hline Female & 14 & 20.3 \\
\hline Total & 69 & 100.0 \\
\hline \multicolumn{3}{|l|}{ Age: } \\
\hline 25 and below & - & - \\
\hline $26-35$ & 24 & 34.8 \\
\hline $36-45$ & 23 & 33.3 \\
\hline $46-55$ & 18 & 26.1 \\
\hline Above 55 & 4 & 5.8 \\
\hline Total & 69 & 100.0 \\
\hline \multicolumn{3}{|l|}{ Education: } \\
\hline B. Pharm/B.Sc. & 49 & 71.0 \\
\hline Masters degree & 12 & 17.4 \\
\hline Ph.D. & 6 & 8.7 \\
\hline Others & 2 & 2.9 \\
\hline Total & 69 & 100.0 \\
\hline
\end{tabular}

Table 2: Respondents by Years in Entrepreneurship/Employment

\begin{tabular}{|c|c|c|c|c|}
\hline \multirow[t]{2}{*}{ Year } & \multicolumn{2}{|c|}{ Entrepreneur Pharmacists } & \multicolumn{2}{|c|}{ Employee Pharmacists } \\
\hline & No & $\%$ & No & $\%$ \\
\hline Less than 2 & 3 & 8.8 & 8 & 22.9 \\
\hline $2-5$ & 7 & 20.6 & 9 & 25.7 \\
\hline $6-10$ & 8 & 23.5 & 6 & 17.1 \\
\hline $11-15$ & 10 & 29.4 & 4 & 11.4 \\
\hline $16-20$ & 5 & 14.7 & 3 & 8.6 \\
\hline $21-25$ & 1 & 2.9 & 3 & 8.6 \\
\hline Above 25 & - & - & 2 & 5.7 \\
\hline Total & 34 & 99.9 & 35 & 100.0 \\
\hline
\end{tabular}

employee pharmacists was 12.86 with a standard deviation of 3.51, while entrepreneur pharmacists had a mean score of 15.56 with a standard deviation of 3.69. The mean locus of control score for entrepreneur pharmacists was significantly different from that for employee pharmacists $(P<0.01)$. Entrepreneur Pharmacists had higher scores on the locus of control scale indicating higher locus of control internality than employee pharmacists.

\section{DISCUSSION}

This result is as expected. It confirms the results of earlier studies that entrepreneurs are more likely to be characterised by locus of control that even though both entrepreneur pharmacists and employee pharmacists are high on locus of control internality, entrepreneur pharmacists are expected to exhibit more internality than employee pharmacists because of the need on the part of the former to be more proactive, innovative and to exert greater efforts to control the uncertain conditions facing the firm ${ }^{18}$.

The result of this study is perhaps more significant because it provides some data on locus of control in a non-western society which is also generally categorised as developing. Mueller and Thomas $^{17}$ conducted a 9-country study of the entrepreneurial orientation of 
University students measuring among others, the locus of control of the respondents. The authors concluded that as the cultural distance from the United States increases, the degree to which a person feels in control of his or her destiny diminishes. They suggested that locus of control is not a distinguishing trait of entrepreneurs (universally) but a culture-specific quality linked to Hofstede's ${ }^{23}$ individualism.

Recently Jacob questioned the utility of Hofstede's typology arguing that national cultures are too complex to be explained in terms of unilinear dimensions ${ }^{24}$. National cultures are not themselves homogenous which means that a grievous error will be committed if we assume that in the so-called collectivist national culture, individuals would generally be characterised by locus of control externality. Our study shows, contrary to Mueller and Thomas proposition $^{17}$, that locus of control distinguishes entrepreneur pharmacists from employee pharmacists in a non-western society.

Boone, Brabander, Gerits and Willeme showed that locus of control is correlated with short-term expectancies but not with long-term expectancies $^{25}$. This implies that locus of control may not be a culturally-specific personality construct. The possibility exists that through experiential learning or demonstration, people can see how their behaviours determine the outcomes they experience and over time, exhibit more locus of control internality. The demonstration effect has worked in agriculture, family planning, etc. and has great potential particularly among young persons. Carefully selected case materials and experiential learning exercises will be useful in this respect.

The result of this study has implications for curriculum development in entrepreneurship. The implications may at first be obscured by the fact that locus of control is a stable personality construct which may be difficult to change in the short-run. However, Luthje and Franke proposed in their structural model of entrepreneurship intent that the intention to become an entrepreneur was dependent on attitude towards entrepreneurship ${ }^{26}$. The attitude was in turn, dependent on risk taking propensity and locus of control. Testing this model, the authors confirmed that while risk taking propensity had a very strong influence on attitude towards entrepreneurship, that of locus of control was fairly high. The conclusion drawn from the study was that improvement of students attitude towards entrepreneurship could enhance the number of graduates who want to start their own businesses.

Thus, an entrepreneurship course in pharmacy programmes could be designed with the aim of enabling students to perceive entrepreneurship as a desirable and rewarding career path. This can be achieved by focusing on success stories of pharmacist entrepreneurs, using such pharmacist entrepreneurs as role models and as adjunct lecturers. The course should also provide opportunity for students to discuss how the choice of strategy impacts on performance in business transactions. Such discussions, based on case materials or carefully selected readings, help to strengthen perceptions of the linkage between behaviour and outcomes.

\section{Limitations of the Study}

The enlarged version of Rotter's I-E scale has been used extensively in the western world and the reliability of the instrument was reported to be high. To our knowledge, the reliability of the instrument has not been examined in a nonwestern setting like Nigeria. The reliability of the instrument was not examined in this study.

The study was conducted in two cities in the South-South Zone of Nigeria. While every effort was made to reach the subjects in these cities, the procedure adopted was tedious and had its limitations. Off the street pharmacies and others located far away from the city centres could not be included in the sample. The use of mailquestionnaire was ruled out because the postal system is inefficient.

\section{CONCLUSION}

This study showed that locus of control was a distinguishing factor among qualified pharmacists who chose to become entrepreneurs and those who chose employee status in organisations. Those who showed more locus of control internality are more likely to opt 
for entrepreneurial roles rather than employee roles. While an earlier study concluded that locus of control is a culture-specific quality linked to individualism, the results of this study provide some evidence that this may not be the case. In non-western societies characterised by collectivism, locus of control was still found to distinguish between entrepreneurs and nonentrepreneurs.

Locus of control has been found to be associated with short-term expectancies and not with long-term expectancies. Based on this, it was argued that appropriate techniques can be used to clarify and strengthen an individual's perception that his/her skills and competencies play an important role in determining the outcomes of his/her efforts.

Pharmacy programmes will benefit from entrepreneurial education. It will enhance the capacity of graduates to provide more innovative pharmaceutical services to society either as owners of pharmaceutical businesses or as managers in such operations. Understanding of the critical role of locus of control and development of positive attitude towards entrepreneurship should be an important component of such an educational process.

\section{REFERENCES}

1. Shapero, Albert and Lisa Sokol: The Social Dimensions of Entrepreneurship. In: Kent, Calvin A, Sexton, Donald L. and Vesper, Karl H. (Eds), Encyclopedia of Entrepreneurship. Prentice-Hall Inc, Englewood Cliffs, N.J. 1982, 72-90.

2. Wickham, Philip A. Strategic Entrepreneurship: A Decision-Making Approach to New Venture Creation and Management. Pitman Publishing, London, 1998, 21-23.

3. Stewart, Jr. Wayne H, Carland, John C, Carland, James W, Watson, Warren E, and Sweo, Robert. Entrepreneurial Dispositions and Goal Orientations: A Comparative Exploration Of United States and Russian Entrepreneurs. JSBM, 2003, 41(1), 27-46.

4. Maher, Pat. Promoting Female Entrepreneurship: Implication for Education, Training and Policy. ICSB Bulletin, 2003, 45(1), 4-5.

5. Carland, JW, Hoy, F, Boulton, WR And Carland, JA. Differentiating Entrepreneurs from Small Business Owners: A Conceptualization. Academy of Management Review, 1984, 9(2), 354-359.
6. Gasse, Yvon. Elaborations on the Psychology of the Entrepreneur. In: Kent, Calvin A, Sexton, Donald L, and Vesper, Karl H, (Eds), Encyclopedia of Entrepreneurship. Prentice-Hall Inc, Englewood Cliffs, N.J. 1982, 57-66.

7. Stewart, Jr. WH, Watson, WE, Carland, JC And Carland, JW. A Proclivity for Entrepreneurship: A Comparative Study of Entrepreneurs, Small Business Owners and Corporate Managers. J. of Business Venturing, 1999, 14(20), 189-214.

8. Stankiewicz, Rikard. Academics and Entrepreneurs: Developing University-Industry Relations. Frances Pinter (Publishers), London, 1986, 86.

9. Drucker, Peter F. Innovation and Entrepreneurship. Butterworth/ Heinemann, Oxford, 1985, 129-134.

10. Covin, JG, And Sleovin, DP. The Influence of Organisational Structure on the Utility of an Entrepreneurial Management Style. J. of Management Studies, 1988, 25(3), 217-234.

11. Hindle, Kevin and Cutting, Neil. Can Applied Entrepreneurship Education Enhance Job Satisfaction and Financial Performance? An Empirical Investigation in The Australian Pharmacy Profession. JSBM, 2002, 40(2), 162-167.

12. Erah, Patrick O. and Nwazuoke, James C. Identification of Standards of

Pharmaceutical Care in Benin City. TJPR, 2002, 1(2), 55-66.

13. Oparah, Azuka C and Eferakeya, Adego E. Attitudes of Nigerian Pharmacists Towards Pharmaceutical Care. Pharm World Sci, 2005, 27, 208-214.

14. Rotter, JB. Generalised Expectancies for Internal Versus External Control of Reinforcement. Psychological Monographs, 1966, 80.

15. Bonnet, $C$ And Furnham, A. Who Wants to be an Entrepreneur? A Study of Adolescents Interested In a Young Enterprise Scheme. J. of Economic Psychology, 1991, 13(3), 465-478.

16. Gray, Judy H. A Predictive Model of Small Business Success. Proceedings of the Academy of Entrepreneurship, Allied Academics International Conference, Las Vegas, Nevada. 1998 October, 16-23.

17. Mueller, SL and Thomas, AS. Culture and Entrepreneurship Potential: A Nine Country Study of Locus of Control and Innovativeness. J. of Business Venturing, 2001, 16, 51-75.

18. Praag, Mirjam Van, Sluis, Justin van der, Witteloostuijn, Arjen van. The Impact of the Locus of Control Personality Trait on the Earnings of Employees vis-à-vis Entrepreneurs. Tinbergen Institute Discussion Paper li 2004-130/3 [http://www.tinbergen.nl (March,2005)].

19. Brockhaus, Sr., Robert, $H$. The Psychology of the Entrepreneur. In: Kent, Calvin A, Sexton, Donald L And Vesper, Karl H (Eds), Encyclopedia of Entrepreneurship. Prentice-Hall, Inc, Englewood Cliffs, N.J., 1982, 39-57.

20. Bindwell, Stephen Wayne and Sullivan, Donald Lawrence. Locus of Control of Pharmacy Owners and Staff Pharmacists. J. of Social And Administrative Pharm. 2003, 20(4), 151-153. 